\title{
Comparative analysis of programmed cell death pathways in filamentous fungi
}

\author{
Natalie D Fedorova*1, Jonathan H Badger ${ }^{1}$, Geoff D Robson², \\ Jennifer R Wortman ${ }^{1}$ and William C Nierman ${ }^{1,3}$
}

Address: ${ }^{1}$ The Institute for Genomic Research, 9712 Medical Center Drive, Rockville, MD 20850, USA, ${ }^{2}$ Faculty of Life Sciences, 1.800 Stopford Building, University of Manchester, Manchester M13 9PT, UK and ${ }^{3}$ The George Washington University School of Medicine, Department of Biochemistry and Molecular Biology, 2300 Eye Street, NW Washington, DC 20837, USA

Email: Natalie D Fedorova* - natalief@tigr.org; Jonathan H Badger - jbadger@tigr.org; Geoff D Robson - geoff.robson@man.ac.uk; Jennifer R Wortman - jwortman@tigr.org; William C Nierman - wnierman@tigr.org

* Corresponding author

Published: 08 December 2005

BMC Genomics 2005, 6:177 doi:10.1/86/147|-2/64-6-177
Received: 20 September 2005

Accepted: 08 December 2005

This article is available from: http://www.biomedcentral.com//47I-2164/6/I77

(C) 2005 Fedorova et al; licensee BioMed Central Ltd.

This is an Open Access article distributed under the terms of the Creative Commons Attribution License (http://creativecommons.org/licenses/by/2.0), which permits unrestricted use, distribution, and reproduction in any medium, provided the original work is properly cited.

\begin{abstract}
Background: Fungi can undergo autophagic- or apoptotic-type programmed cell death (PCD) on exposure to antifungal agents, developmental signals, and stress factors. Filamentous fungi can also exhibit a form of cell death called heterokaryon incompatibility $(\mathrm{HI})$ triggered by fusion between two genetically incompatible individuals. With the availability of recently sequenced genomes of Aspergillus fumigatus and several related species, we were able to define putative components of fungi-specific death pathways and the ancestral core apoptotic machinery shared by all fungi and metazoa.

Results: Phylogenetic profiling of $\mathrm{HI}$-associated proteins from four Aspergilli and seven other fungal species revealed lineage-specific protein families, orphan genes, and core genes conserved across all fungi and metazoa. The Aspergilli-specific domain architectures include NACHT family NTPases, which may function as key integrators of stress and nutrient availability signals. They are often found fused to putative effector domains such as Pfs, SesB/LipA, and a newly identified domain, HET-s/LopB. Many putative $\mathrm{HI}$ inducers and mediators are specific to filamentous fungi and not found in unicellular yeasts. In addition to their role in $\mathrm{HI}$, several of them appear to be involved in regulation of cell cycle, development and sexual differentiation. Finally, the Aspergilli possess many putative downstream components of the mammalian apoptotic machinery including several proteins not found in the model yeast, Saccharomyces cerevisiae.
\end{abstract}

Conclusion: Our analysis identified more than 100 putative PCD associated genes in the Aspergilli, which may help expand the range of currently available treatments for aspergillosis and other invasive fungal diseases. The list includes species-specific protein families as well as conserved core components of the ancestral PCD machinery shared by fungi and metazoa.

\section{Background}

Aspergillus fumigatus is the most prevalent causative agent of invasive aspergillosis in immunocompromised patients and it can also cause asthma, allergies, and mycotoxicosis [1]. Other species of this genus including Neosartorya fischeri (teleomorph of A. fischerianus), A. flavus, A. terreus, 
Table I: Putative $\mathrm{HI}$ inducers

\begin{tabular}{|c|c|c|c|c|c|c|}
\hline Protein/Domain & ASP & SOR & Scer & Spom & BAS & Biological function/process \\
\hline HET-C & I & I & 0 & 0 & 1 & Unknown \\
\hline RNRI & 1 & I & I & 1 & 1 & Cell cycle control \\
\hline HET-C2 & I & I & 0 & 0 & I & Cell cycle controla, sphingolipid sensing \\
\hline MAT-I/2 & $1-2$ & I & 2 & 2 & 0 & Regulation of sexual differentiation \\
\hline HET & $7-38$ & $38-94$ & 0 & 0 & 0 & Signaling, regulation of sexual differentiation \\
\hline HET-s/LopB & $0-1$ & $1-7$ & 0 & 0 & 0 & Unknown \\
\hline $\mathrm{NACHT}$ & $12-19$ & $2-18$ & 0 & 0 & 0 & Signaling, NTP binding, oligomerization \\
\hline $\mathrm{Pfs}+\mathrm{NACHT}$ & $5-7$ & I & 0 & 0 & 0 & Signaling, nucleoside metabolism \\
\hline
\end{tabular}

ASP, A. fumigatus, N. fischeri, A. oryzae, A. nidulans; SOR, N. crassa, G. zeae, and M. grisea; BAS: Cryptococcus neoformans and Ustilago maydis; Scer, S. cerevisiae; Spom, Schizosaccharomyces pombe; ${ }^{a}$, putative function.

A. niger, and A. nidulans can also cause diseases in humans, animals and plants all over the world [2]. Despite the medical and agricultural importance of this genus, limited antifungal therapies are available due to high toxicity, low efficacy rates, and growing drug resistance [3]. Activation of endogenous programmed cell death (PCD) reactions is a promising approach to combat invasive aspergillosis and other fungal diseases. Several antifungal agents including amphotericin B and rapamycin have been shown to induce cell death cascades in filamentous fungi [4-7]. Better understanding of these pathways might provide the basis for the development of novel anti-fungal therapeutics against aspergillosis and give further insights into evolution of programmed cell death in the eukaryotic cell.

Several different cell death programs seem to exist in parallel in fungi and often resemble mammalian apoptosis and yeast autophagy [8-11]. The best studied form of programmed cell death in filamentous fungi is heterokaryon incompatibility (HI) that can be triggered by cellular fusions between hyphae of incompatible individuals during vegetative growth or between incompatible germlings during the establishment of fungal colonies [12]. These fusion between two individuals with incompatible het (heterokaryon incompatibility) loci triggers the HI reaction characterized by growth inhibition, repression of asexual sporulation, hyphal compartmentation and death in the heterokaryotic cell $[13,14]$. Although HI is ubiquitous in filamentous fungi, its biological significance and evolutionary origin is still unknown. It has been proposed to serve as a self/nonself recognition system responsible for limiting genetic exchange and horizontal transfer of cytoplasmic infectious elements [15-17]. Coincidentally, one of the $\mathrm{HI}$ inducers in $P$. anserina is a prion capable of infectious propagation [18].

Much of what is known about the underlying mechanisms of programmed cell death in fungi comes from only three species, Saccharomyces cerevisiae, P. anserina and N. crassa. With the availability of the newly sequenced genomes of $A$. nidulans (J. Galagan et al., in press), $A$. oryzae (M. Machida et al., in press), A. fumigatus Af293 (W. Nierman et al., in press), and N. fischeri (W. Nierman, unpublished) we were able to identify their putative PCD effectors and mediators. In this study, we applied a BLASTp-plus-phylogeny reconstruction approach to survey the Aspergillus spp. genomes for homologs of characterized programmed cell death proteins from fungi and animals. Several fungi-specific families as well as components of the core cell death machinery shared by filamentous fungi and metazoan were identified.

\section{Results and discussion \\ Inducers of HI-triggered PCD}

Several components of the HI reaction encoded by the het genes, the HI suppressor genes, and the HI-induced genes have been characterized at the molecular level in $P$. anserina and $N$. crassa. In natural populations of $P$. anserina, $N$. crassa and Cryphonectria parasitica, the functional het genes exist as two or more polymorphic alleles conferring alternative specificities [19-22]. Different loci may be responsible for triggering the HI reaction in these two and other fungal species. Heterocomplex formation between alternative het gene products is thought be a common theme in nonself recognition during allelic and non-allelic HI $[23,24]$. One of the genetically (and potentially physically) interacting partners is often a HET domain protein [15] that may interact with well-conserved proteins playing important roles in development and differentiation (Dementhon and L. Glass, unpublished).

Although at least eight loci have been implicated in $\mathrm{HI}$ in A. nidulans [25], none of them has been characterized at the molecular level. To identify putative HI-associated proteins in the Aspergilli, we first searched completely sequenced fungal genomes using known inducers and mediators of heterokaryon incompatibility as BLASTp queries. We examined the domain composition and phyletic distribution of the BLASTp hits and built phylogenetic trees for several protein families. We also applied domain fusion analysis to several so called Rosetta Stone 
proteins with unusual domain composition to infer protein domain interactions and functional linkage between putative $\mathrm{HI}$-associated proteins identified in the Aspergilli proteomes.

\section{HET-C2 proteins}

Our database BLASTp searches identified orthologs of $P$. anserina HET-C2 [26], in all filamentous fungal genomes sequenced to date (Table 1 ). The family also has a high level of sequence conservation and wide phyletic distribution in other taxa. HET-C2 orthologs are found in several Saccharomycetes, including Debaryomyces hansenii and Kluyveromyces lactis, (Fig. 1). Yet no homologs are detected in S. cerevisiae and S. pombe, suggesting a gene loss in some yeast lineages. HET-C2 homologs are also present in most animals and plants.

The high level of conservation among the HET-C2 family members is consistent with the important role these proteins may play in the glycosphingolipid and sphingosine metabolism and possibly in regulation of cellular stress responses. HET-C2 shows significant similarity to human GLTP [27] and Arabidopsis thaliana ACD11 [28] proteins, which catalyze the intermembrane transfer of glycosphingolipids and sphingosines, respectively. ACD11 has also been shown to function in PCD and pathogen defense in plants. In Aspergilli, sphingosines have been also shown to induce an apoptosis-like PCD [4] and to affect cell cycle progression [29]. $P$. anserina HET-C2 was proposed to act as a glycolipid metabolite sensor in addition to its role in glycolipid transfer, regulation of ascospore maturation, and triggering $\mathrm{HI}[26,30]$. The high level of sequence conservation in this family, suggests that the role of HET-C2 orthologs in the Aspergilli PCD pathway is likely to be similar.

\section{HET-C proteins}

Further analysis showed that all Aspergillus species have direct orthologs of $N$. crassa HET-C [31] and its close homolog of unknown function (Table 1). The phylogenetic tree has a bipartite division resulting from an early gene duplication event predating the separation of Eurotiomycetes and Sordariomycetes (Fig. 2). HET-C is orthologous to A. nidulans HetC and homologous to TinC [32]. The HET-C domain is found in many ascomycetes and basidiomycete species, but surprisingly in only one yeast species, Yarrowia lipolytica, which clusters together with HET-C homologs from basidiomycete species. Unexpectedly, a partial HET-C domain is also present in several epiphytic and symbiotic bacteria including two gammaproteobacteria, Pseudomonas syringae [GenBank: AAY39263 and GenBank: AAO58004], a cyanobacterium, Nostoc punctiforme [GenBank: ZP 00106220], and an actinomycete of the genus Frankia [GenBank: ZP 00567177]. The phylogenetic tree of the conserved N- terminal portion of HET-C shows that the bacterial proteins form a coherent clade with a long branch connecting it to the rest of the tree. We had to exclude the Nostoc punctiforme protein from the phylogenetic analysis because it was too divergent, but it also showed more similarity to the bacterial proteins.

Based on the current tree topology, the origin of the bacterial homologs is not clear. It can be attributed to vertical inheritance from the last common ancestor between bacteria and fungi followed by massive gene loss in most bacterial and yeast lineages. Alternatively, it can be explained by horizontal transfer of the ancestral het-C gene from epiphytic fungi followed by rapid divergence in bacteria. In the latter case, the gene must have persisted in bacterial populations by conferring a selective advantage to the recipients. Since heterologous expression of an N. crassa het-C allele was also shown to trigger an HI-like growth defect in P. anserina [21], the het-C homologs in P. syringae or related species may induce growth inhibition in epiphytic filamentous fungi and thus facilitate substrate defense.

$N$. crassa polypeptides encoded by the het-C alleles of alternative specificity were shown to form a heterocomplex localized to the plasma membrane during the HI reaction [23]. It has a putative signal peptide, a conserved HET-C domain and a divergent C-terminal glycine-rich region, often found in extracellular glycoproteins. The biological role of the HetC proteins in the Aspergilli is unknown. A. nidulans TinC has been shown to stabilize the NimA mitotic kinase required for mitotic entry [32]. A. nidulans strains lacking tinC displayed cold and osmotic sensitivity and overexpression of its truncated form produced growth inhibition, defects in nuclear envelope fission and cell cycle [32]. It is unlikely that either protein triggers the HI reaction in the A. nidulans. Moreover, het-C may not act as a bona fide het gene in other fungal species, since no het-C polymorphism was observed in A. flavus (K. Ehrlich and P. Cotty, unpublished), A. nidulans [32], and $P$. anserina [21] isolates. Nonetheless, expression of the $N$. crassa het-c(PA) allele triggers a growth inhibition similar to the HI reaction in $P$. anserina. If $N$. crassa HET-C has a similar role to TinC, it may explain the growth inhibition effects caused by expression of $N$. crassa (and possibly bacterial) het-c in P. anserina [21].

\section{HET domain proteins}

HET domain [15,33] proteins were identified using the HMMer package as described in Methods. Unlike the ubiquitous HET-C2 family, the HET domain appears to be limited to filamentous ascomycetes and is not detected in yeasts or basidiomycete species (Table 1). In the Aspergilli, the number of HET domain proteins varies from seven in N. fischeri to 38 in A. oryzae. The tree topol- 


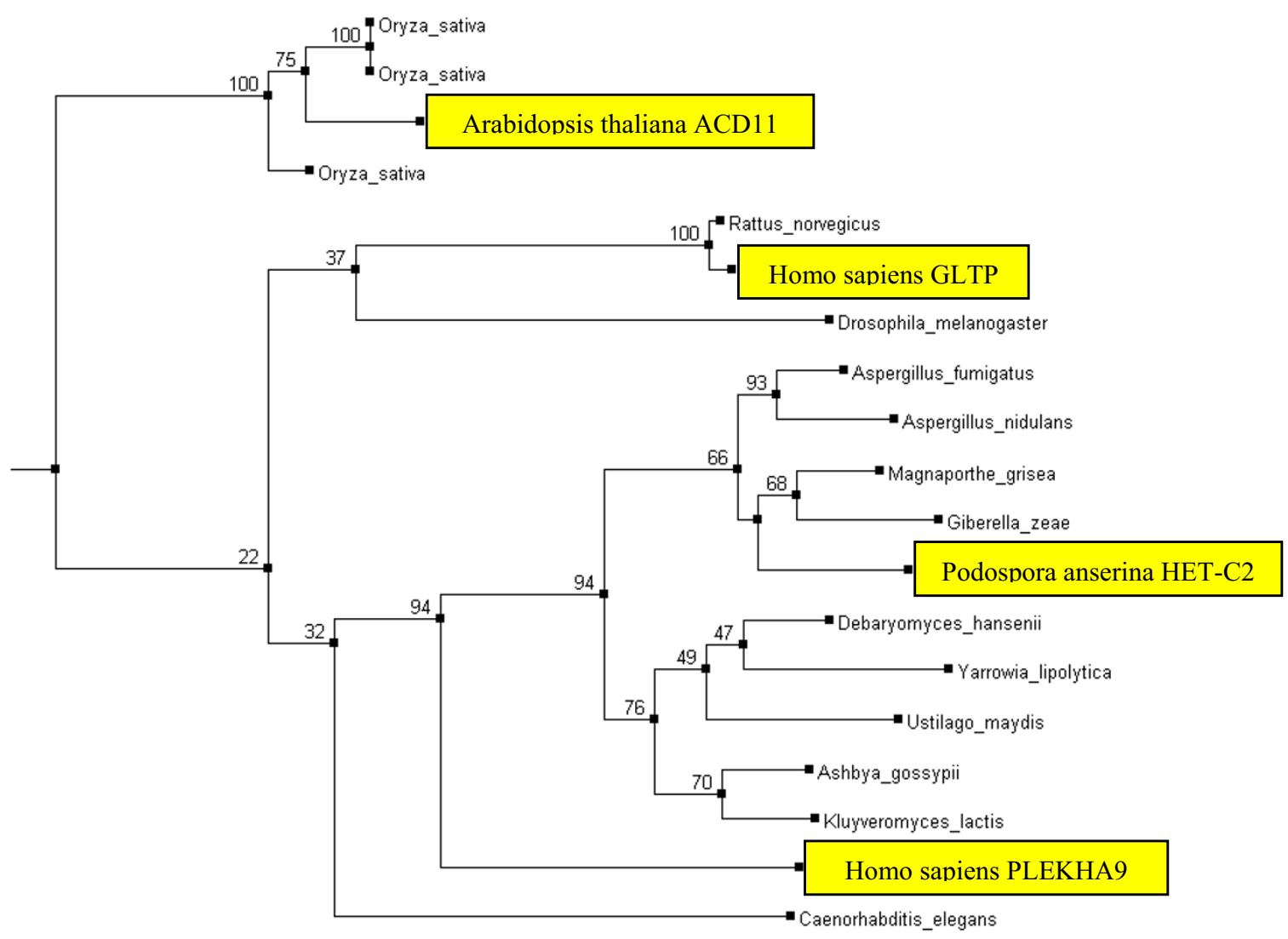

\section{Figure I}

Phylogenetic tree of the HET-C2/GLTPIACD I I family of proteins. Tree reconstruction was performed as described in the Methods section. Experimentally characterized proteins are shown in yellow. The numbers indicate percent bootstrap values for selected internal branches. Hemiascomycete members including Debaryomyces hansenii, Ashbya gossypii, Yarrowia lipolytica, and Kluyveromyces lactis clustered together with the basidiomycete U. maydis.

ogy delineates multiple duplication events in filamentous ascomycetes species followed by rapid diversification and gene loss in several Aspergillus spp. (data not shown). Orthologous relationships within this Aspergillus family are difficult to establish, except for a subfamily of HET and Ankyrin domain proteins, which appear to be related by direct vertical descent (data not shown).

The HET domain expansion in filamentous ascomycetes may represent a niche adaptation strategy to process a large number of similar stimuli associated with defense against pathogens, self/nonself recognition, differentiation, or analogous roles. It is found in N. crassa HET-6 and TOL and in $P$. anserina HET-D and HET-E, and so appears to be critical to the HI reaction in both species (for review see [15]). In P. anserina HET-D and HET-E, HET domains are followed by a NACHT domain and multiple WD repeats, while $N$. crassa proteins contain a coiled-coil domain and LRR repeats, instead (see Figure 3). In addition to HET-6 and TOL, N. crassa has about 50 other HET domain proteins, whose role in the HI reaction if any is as yet unknown.

\section{Identification of the HET-s/LopB domain}

Initial BLASTp searches using the $P$. anserina HET-s sequence [34] as a query revealed homologs in A. nidulans, P. chrysogenum, M. grisea, N. crassa and G. zeae (Table 1). Iterative PSI-BLAST searches identified a new domain that includes more proteins from the same species plus a pathogenicity protein, LopB, from the Dothideomycete fungus Leptosphaeria maculans [35]. For LopB and most other members of this family, sequence similarity is limited to the N-terminal globular domain of HET-s (Fig. 4) [36]. Two members from A. nidulans and N. crassa have an 


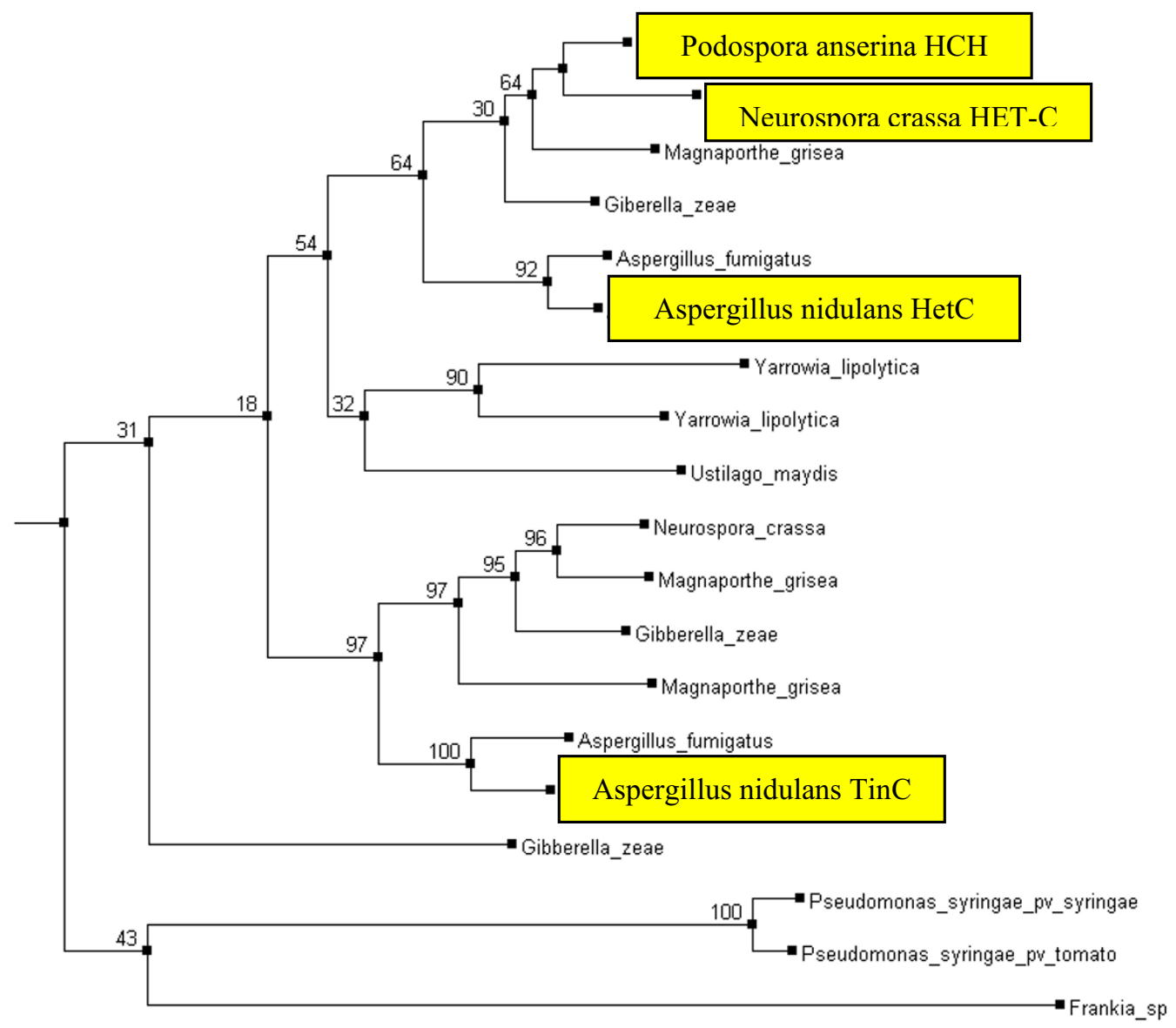

Figure 2

Phylogenetic tree of the HET-C family of proteins. Tree reconstruction was performed as described in the Methods section. Experimentally characterized proteins are shown in yellow. The numbers indicate percent bootstrap values for selected internal branches.

adjacent NACHT domain (described below) at the N- and C-terminus, respectively.

As mentioned earlier, HI was proposed to act as a self/ nonself recognition system responsible for limiting the spread of numerous infectious elements in natural populations [15-17]. Coincidentally, HET-s prion behaves as a non-conventional infectious element capable of propagation during anastomosis and sexual reproduction in $P$. anserina [37]. HET-s can exist in two forms: as a normal protein [18] and as an infectious prion [38], capable of propagating as a self-perpetuating amyloid aggregate $[18,36]$. Its rather unexpected similarity to LopB implies that members of the family may have another function unrelated to HI. Although its specific role in L. maculans is unknown, $L o p B^{-}$mutants showed impaired ability to form lesions on oilseed rape [35]. LopB contains a predicted signal peptide suggesting that it is secreted and might con- tribute to the L. maculans pathogenicity by compromising host membranes. The fusions between HET-s/LopB and NACHT domain in N. crassa and A. nidulans suggests that, in other species, proteins containing one of these two domains may physically interact.

\section{STAND domain proteins}

Using $P$. anserina HET-E as a BLASTp query, we identified several proteins containing NACHT domain in the Aspergilli and other filamentous ascomycetes. Further HMMer searches detected two Aspergillus-specific expansions of the STAND domain [39]: NACHT NTPases and NB-ARC ATPases (Table 1). These NTP-binding proteins are often linked to various protein-binding modules such as WD40, Ankyrin or TPR at the C-terminus and a highly divergent nucleoside phosphorylase (Pfs) domain at their $\mathrm{N}$-terminus (Fig. 3). A different type of domain composition is found in several other STAND NTPases. NB-ARC 


\begin{tabular}{|c|c|c|}
\hline \multicolumn{3}{|c|}{ Secondary structure } \\
\hline HET-S & Pans & \\
\hline HET-S & Pans & \\
\hline LopB & Lmac & \\
\hline GI : 39940292 & Mgri & \\
\hline GI : 9453820 & NCra & \\
\hline $\mathrm{GI}: 40745698$ & Anid & \\
\hline GI : 42545766 & Gzea & \\
\hline Secondary st & ctur & \\
\hline HET-S & Pans & \\
\hline HET-S & Pans & \\
\hline LopB & Lmac & \\
\hline GI : 39940292 & Mgri & \\
\hline GI : 9453820 & NCra & \\
\hline $\mathrm{GI}: 40745698$ & Anid & \\
\hline GI : 42545766 & Gzea & \\
\hline Secondary st & cture & \\
\hline HET-S & Pans & \\
\hline HET-S & Pans & \\
\hline LopB & Lmac & \\
\hline GI : 39940292 & Mgri & \\
\hline GI : 9453820 & Nera & \\
\hline GI : 40745698 & Anid & \\
\hline GI : 42545766 & Gzea & \\
\hline Secondary s & cture & \\
\hline HET-S & Pans & \\
\hline HET-S & Pans & \\
\hline LopB & Lmac & \\
\hline GI: 39940292 & Mgri & \\
\hline GI : 9453820 & Nera & \\
\hline GI : 40745698 & Anid & \\
\hline GI : 425 & Gzea & \\
\hline Secondary s & cture & \\
\hline HET- & Pans & \\
\hline HET-S & Pans & \\
\hline LopB & Lmac & \\
\hline GI: 39940292 & Mgri & \\
\hline GI : 9453820 & Ncra & \\
\hline GI : 40745698 & Anid & \\
\hline & & \\
\hline Secondary s & cture & \\
\hline HET-S & Pans & \\
\hline HET-S & Pans & \\
\hline LopB & Lmac & \\
\hline GI : 39940292 & Mgri & \\
\hline GI : 9453820 & Ncra & \\
\hline GI : 407 & Anid & \\
\hline GI : 42545766 & Gzea & \\
\hline
\end{tabular}

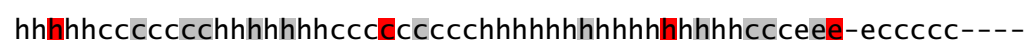
ALNVAGLFNNCVDCFEYVQLGRPFGRDYERCQLRLDIAKARLSRWGEAVK-INDDPR---ALGVAGLFNNCVACFEYVQLGRHFGRDYERCQLRLDIAKVRLSRWGEAVQ-INDDPR---VFSLATQFSTCVEAFNLIHPSKDNDHAQKVALAKLGLQQGRLLIFGDAVG-ISAPPPNIAR VLGVAGLFKSCIDNFDIVVRAKNFGEDFDLLCTQLALQRLRLVLWGESLGLVASPQG---VIGLAGVFKSCVELFGYFSTYRSYGHDYSLLDAKLHVEKAFLLLWADRVRLLHEDYD---LNEQSRLFNDAVQSFEYIQMGSNFGQSFQTSLLKLDVVRLKLTRWGQSVGLANVDDG---ALSVAAIFNNCVDTFEYIQLGRRFGEDFQRYQLKLDLAKTRLGRWGEAIS-INNEPR----

66

66

85

65

335

66

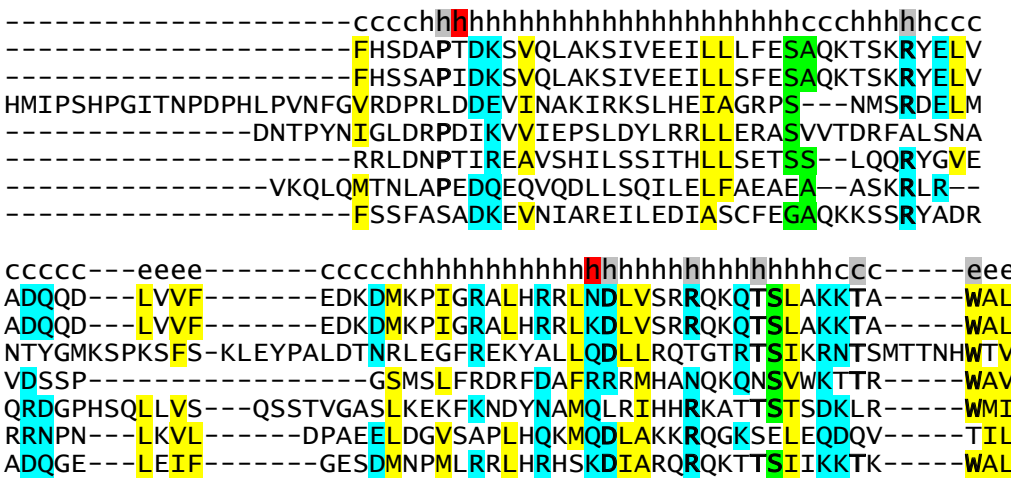

104

104

141

104

102

104

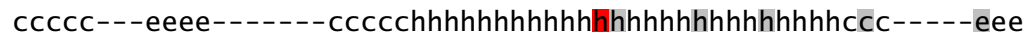
ADQQD---LVVF-------EDKDMKPIGRALHRRLNDLVSRRQKQTSLAKKTA-----WAL ADQQD---LVVF-------EDKDMKPIGRALHRRLKDLVSRRQKQTSLAKKTA-----WAL NTYGMKSPKSFS-KLEYPALDTNRLEGFREKYALLODLLROTGTRTSIKRNTSMTTNHWTV NTY RRNPN---LKVL------DPAEELDGVSAPLHQKMQDLAKKRQGKSELEQDQV-----TIL ADQGE---LEIF------GESDMNPMLRRLHRHSKDIARQRQKTTSIIKKTK-----WAL

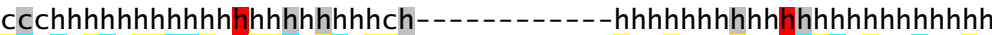
YDGKSLEKIVDQVARFVDELEKAFP---------IEAVCHKLAEIEIEEVEDEASLT

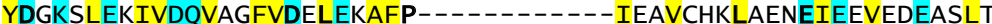
KDGARFNHYVATVRTEVDSLIELMGVKEQVDRGTRSDIRCMAWHPDLTGPIVYODWEKLR HDAAAFKATVDQIKQLVDGLESITG------ TMENLLRRQRAALVGEIESVPDTRSLR VDKDKFNTLIAELSHFTSKLDALLP------GDSSERTVSLLASLIRNEVLSVYKENAKL YEEKNFARLIEDIGELVDGLVDLFPG----------IQEEQRKLCEEEVSGLNANEGAL YDAKSLERTIDQICSWIDELEKLFP-----------EQSAQTQLVEREIEKIDDKPTLE

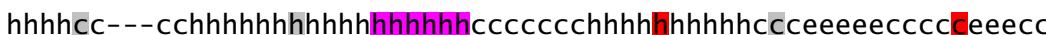
ILKDAA---GGIDAAMSDAAAQKIDAIVGRNSAKDIRTEERARVQLGNVVTAAALHGGIRISD ILKDAA---GGIDAAMSDAAAQKIDAIVGRNSAKDIRTEKRARVQLGNVVTAARLHGEIRISD LIREACEVDYPEYIEVADSALKYINEELK------ETSLAKRRASLGLAVPKESPAGGRRKSD LIQMAS-----GSSNDRDASTRL ISDVAS---HQLSLVKSSSRSSFSRIVGSGSLYHTTPLYP LPQQAA----DGRLEGNDILQEARDQDRALKSL-WFRCMDDRKDSVSPAHVKTLQWALKPACK SLLKEV--AAGQDKLLSDTVVKVIQSTTS-YTNSVVFSGPNSGFQIGNNSGKI---SGVRFGG ALKDAA---SGVDPVMEDAVQRKLNMIEGHNSAEFVNLEGSAKFLVGNVFSEKFLQRDVLLNDR

ccccceeeeecccceeeeecccccccccc QTTNSVETVVGKGESRVLIGNEYGGKGFWDN QTTNSVETVVGKGESKVLIGNEYGGKGFWDN YDIRTAPPKFAAADKTHLOLSAERACDPNSG RAQLQRASDRPMFESCSLHLLPRLPVARITR REGYEAE-WDDLSEWLRSGTGVYWICGKAGS -TKNSMRTVSATNQSRLQVGNVYGGRGIWED

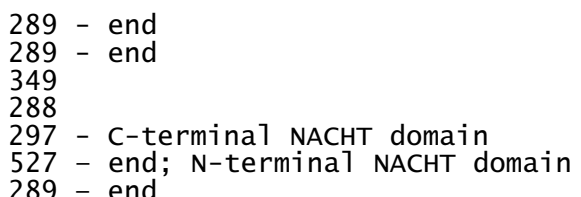

\section{Figure 4}

Multiple alignment of the HET-s/LopB protein family. The first line in the alignment shows the prediction of secondary structure content: $\mathrm{h}$ for helical, e for extended, $\mathrm{c}$ for coiled. Residues conserved among several proteins are marked with gray shading. The polymorphic positions in HET-s and HET-S proteins are shown with red shading. Proteins are listed under their unique GenBank identifiers (first left column). Species are indicated in the second from left column: Pans, Podospora anserina; Lmac, Leptosphaeria maculans; Mgri, Magnaporthe grisea; Ncra, Neurospora crassa; Anid, Aspergillus nidulans, Gzea, Gibberella zeae. Yellow shading indicates uncharged amino acids (A, I, L, V, M, F, Y, or W). Conserved small residues (G, A, or S) are shown in green. Charged residues ( $D, E, K, R, N$, or $Q$ ) are shown in blue. The residues corresponding to the proteinase $K-$ resistant amyloid core in P. anserina Het-s are highlighted in purple and underscored.

can fused to a LipA domain found in putative serine esterases and in the SesB protein from Nectria haematococca [40]. Some NACHT NTPases are linked to the HET-s/LopB domain described above. The orthologous relationships within the two STAND domain expansions are difficult to establish since the proteins are highly divergent and exhibit uneven phyletic distribution. They also appear to have undergone multiple domain shuffling events as well as lineage-specific gene loss and expansions during the 


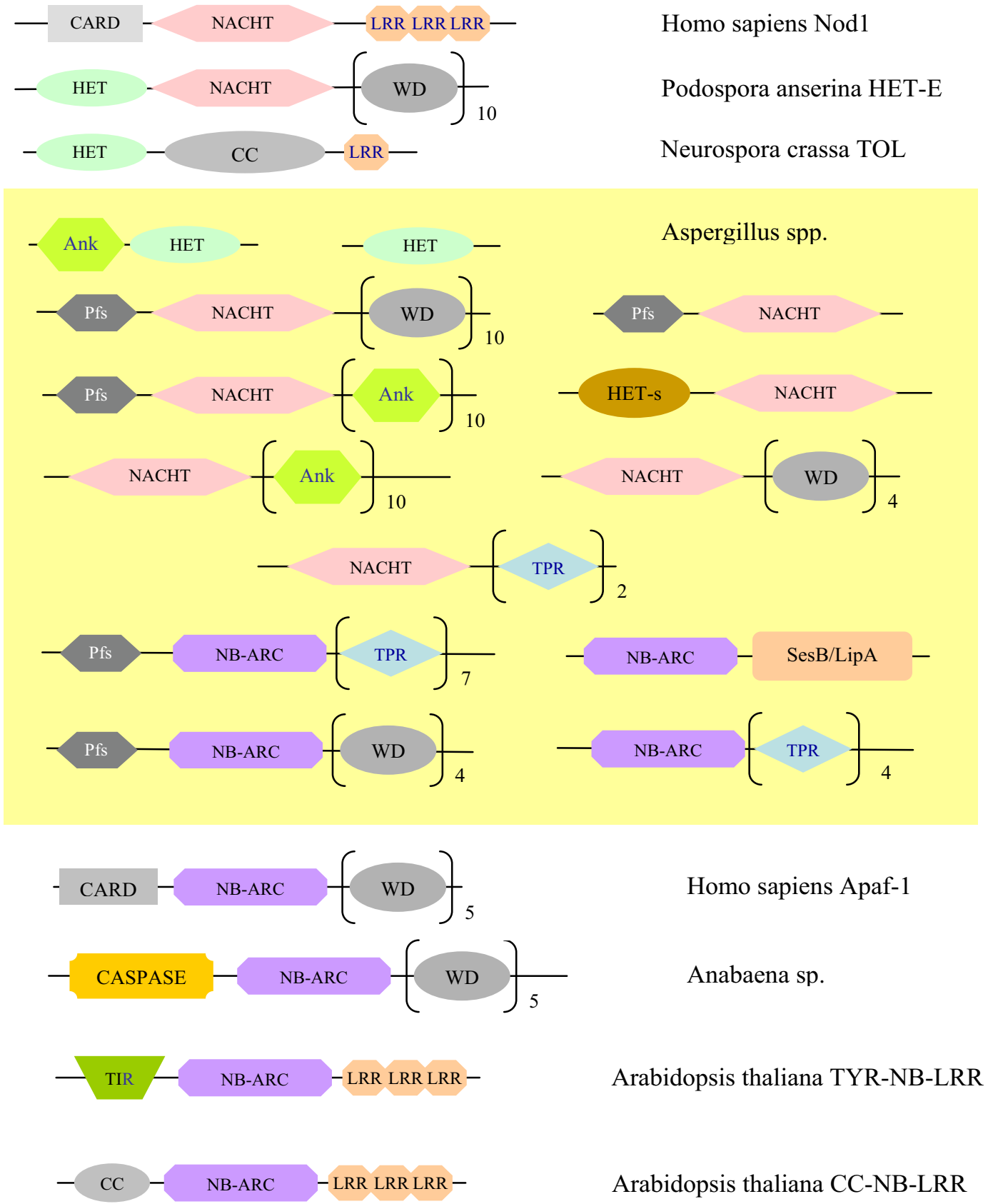

\section{Figure 3}

Domain organization of NACHT, HET-s/LopB, and HET domain proteins. Each shape indicates a specific conserved domain. Fused domains that form a single polypeptide chain are connected by a horizontal line. Aspergilli proteins are located in the area with the yellow background. Ank, Ankyrin domain; CARD, caspase recruitment domain; CC, coiled coil domain; HET, HET domain; HET-s/LopB, new domain found in HET-s and LopB proteins; LRR, leucine-rich repeat; NACHT, NACHT domain; NB-ARC, NB-ARC domain; Pfs, nucleoside phosphorylase domain; SesB/LipA, SesB/LipA domain, found in putative serine esterases and in signaling protein SesB from Nectria haematococca; TIR, toll-interleukin receptor domain, TPR, tetratricopeptide repeat; WD, WD40 domain, found in eukaryotic proteins with various functions including adaptor/regulatory modules in signal transduction; typically contains the WD dipeptide at its $\mathrm{C}$-terminus and is 40 residues long. Figure is not drawn to scale. 
Table 2: Putative HI mediators

\begin{tabular}{|c|c|c|c|c|c|c|}
\hline Protein & ASP & SOR & Scer & Spom & BAS & Biological function \\
\hline IDI- I & 0 & 0 & 0 & 0 & 0 & Unknown \\
\hline IDI-2 & $0-1$ & $0-1$ & 0 & 0 & 0 & Unknown \\
\hline IDI-3 & 0 & 0 & 0 & 0 & 0 & Unknown \\
\hline IDI-4, JlbA & 1 & 1 & 0 & 0 & 0 & Regulation of transcription in response to nutritional stress \\
\hline VIB-I & $1-2$ & 1 & 0 & 0 & 0 & Regulation of sporulation \\
\hline MOD-D, GpaB, GanB & 1 & 1 & 1 & 0 & $\mathrm{I}$ & Regulation of asexual sporulation, pathogenicity, G-protein signaling \\
\hline MOD-A & $0-1$ & $1-3$ & 0 & 0 & 0 & Regulation of sexual differentiation \\
\hline MOD-E, HSP90 & 1 & 1 & 2 & 1 & 2 & Regulation of sexual differentiation, life span, protein folding \\
\hline IDI-7, AUT7 & 1 & 1 & 1 & $\mathrm{I}$ & 1 & Regulation of sexual differentiation, autophagy \\
\hline IDI-6, Alp2p & 1 & 1 & 2 & 2 & 1 & Regulation of sexual differentiation, autophagy \\
\hline
\end{tabular}

ASP, A. fumigatus, N. fischeri, A. oryzae, A. nidulans; SOR, N. crassa, G. zeae, and M. grisea; BAS: C. neoformans and U. maydis; Scer, S. cerevisiae; Spom, S. pombe.

evolution of the Aspergilli as well as other filamentous fungi.

As mentioned earlier, one of N. crassa NACHT domain protein is linked to the HET-s/LopB domain. P. anserina HET-D and HET-E are fused to the HET domain and 11 WD40 repeats, which determine their allelic specificity [41]. HET-E has been shown to genetically (and potentially physically) interact with HET-C2 to trigger incompatibility in $P$. anserina suggesting that the interaction may activate the ceramide stress response pathway [24]. Similar to the HET domain expansion, the two STAND domain expansions may represent a niche adaptation strategy in filamentous ascomycetes. The multiple fusions involving STAND domains in filamentous fungi may be responsible for the enhancement of their repertoire of signal-transducing interactions, linking preexisting signaling pathways, or integrating multiple signals.

Although their specific biological role is unknown, several functional inferences can be made regarding the role of the STAND domain proteins in the Aspergilli. Despite the variability of their domain architecture, the regulatory/signaling function of STAND NTPases seems to be conserved from fungi to man to possibly bacteria. The domain has been implicated in hetero-oligomerization and signal transduction during apoptosis, inflammatory and pathogen responses in animals and plants, and in transcriptional regulation of secondary metabolism in bacteria [42-44]. Similar to their fungal counterparts, animal and plant members of the superfamily tend to be fused to death effector domains at the $\mathrm{N}$-terminus and to repetitive protein binding/regulatory modules at the C-terminus [39].

Other observations suggest that Pfs and STAND domain fusion proteins in the Aspergilli may play a regulatory or signaling role. In plants, the Pfs domain was found in several stress-inducible enzymes [42]. The Pfs domain is also found in bacterial methylthioadenosine/S-adenosylhomocysteine (MTA/SAH) nucleosidases and phosphoribosyltransferases [45]. The bacterial nucleosidases function in methionine salvage pathway and control intracellular levels of MTA/SAH and, in several cases, production of a quorum-sensing signaling molecule [46]. In animals, MTA has been shown to affect many critical responses including regulation of gene expression, proliferation, differentiation and apoptosis [47].

The NB-ARC and LipA as well as NACHT and HET-s/LopB domain fusion proteins may function as bistable switches in signaling cascades. A putative serine esterase domain, LipA, is found in the SesB protein implicated in bistability of developmental signaling cascades in Nectria haematococca [40]. Incidentally, ses $B$ is adjacent to a gene, which encodes a NACHT and Ankyrin domain protein. HET-s is also associated with bistability of the HI reaction resulting from the spread of the infectious prion in P. anserina [38].

Another line of evidence implicating this family in integration of developmental, stress, and nutrient availability signals, comes from expression data. At least five NACHT domain proteins appear to be regulated by LaeA in $A$. fumigatus (N. Keller, S. Kim and W. Nierman, unpublished), a putative chromatin-dependent regulator of secondary metabolism, virulence and conidiation [48,49]. A few other putative PCD-associated proteins seem to be affected by LaeA in A. fumigatus, including both metacaspases, bZIP transcription factor JlbA, BAX Inhibitor family protein, $\mathrm{Cu}^{2+} / \mathrm{Zn}^{2+}$ superoxide dismutase SOD1, histone chaperone ASF1, and AMID-like mitochondrial oxidoreductase, some of which are described below.

\section{Mediators of HI-triggered PCD}

In addition to the putative HI inducers, the Aspergilli possess homologs of HI suppressors from $P$. anserina and $N$. crassa (Table 2) [15]. Thus, sequence similarity searches detected orthologs of $N$. crassa VIB-1 [50] and P. anserina 
Table 3: Putative apoptotic mediators (fungal protein homologs)

\begin{tabular}{|c|c|c|c|c|c|c|}
\hline Protein & ASP & SOR & Scer & Spom & BAS & Biological function/process \\
\hline Aiflp & 0 & 0 & 1 & 0 & 0 & Caspase independent apoptosis \\
\hline Stm Ip & 1 & I & i & I & I & Caspase independent apoptosis \\
\hline Cdc6p & I & I & 1 & I & 1 & Cell cycle control, DNA replication \\
\hline Asflp & I & $0-1$ & I & I & I & Cell cycle, chromatin assembly, mating \\
\hline Cdcl3p & 0 & 0 & I & 0 & 0 & Cell cycle control, telomere-binding \\
\hline Cyclp & I & I & 1 & I & 1 & Electron transport, cytochrome c \\
\hline Mrellp & 1 & 1 & 1 & 1 & 1 & Maintenance of genome integrity \\
\hline $\operatorname{Rad} 50 p$ & I & I & I & I & I & Maintenance of genome integrity \\
\hline Ycalp & $2-3$ & $1-4$ & 1 & I & $1-2$ & Metacaspase \\
\hline Sfklp & I & I & I & I & I & Mitochondrial death pathway \\
\hline Atp4p & I & I & I & I & I & Mitochondrial FIFO ATP synthase \\
\hline DAP3 & I & i & 1 & I & 1 & Mitochondrial fragmentation \\
\hline $\mathrm{HtrA} 2$ & I & $1-2$ & 1 & 2 & 0 & Mitochondrial homeostasis \\
\hline Lsm4p & I & I & I & I & I & mRNA processing \\
\hline Nsrlp & I & I & 1 & I & I & rRNA processing \\
\hline Hellop & 1 & $0-1$ & 1 & 0 & 0 & Apoptosis \\
\hline Uthlp & i & 1 & 4 & 2 & 0 & Response to stress \\
\hline Sodlp & 1 & 1 & 1 & 1 & 1 & Response to stress \\
\hline $\mathrm{BI}-\mathrm{I}$ & i & i & i & i & i & Response to stress \\
\hline Mras I & 1 & 1 & I & I & I & Regulation of development, signaling \\
\hline $\mathrm{FadA} / \mathrm{GpaA}$ & I & 1 & 1 & 1 & 1 & Regulation of sexual differentiation, sporulation, G-protein signaling \\
\hline Ste4p/CGBI & i & i & I & i & I & Regulation of sexual differentiation, sporulation, G-protein signaling \\
\hline Stel8p & 1 & 1 & I & I & 1 & Regulation of sexual differentiation \\
\hline Ste20p & 1 & $0-1$ & I & I & 1 & Regulation of sexual differentiation \\
\hline Sip3p & I & I & 2 & I & 0 & Regulation of sexual differentiation \\
\hline Sst2p, FlbA & I & $1-2$ & I & I & I & Regulation of sexual differentiation \\
\hline Oxal & 1 & 1 & I & I & I & Regulation of life span, respiratory complex assembly \\
\hline RMPI & I & I & I & I & I & Regulation of development and life span, respiratory complex assembly \\
\hline Laglp & i & 1 & 1 & 2 & I & Sphingolipid-mediated signaling \\
\hline Sarlp, SarA & i & i & i & I & I & Ubiquitin-proteosome system \\
\hline Cdc48p & 1 & 1 & I & I & I & Ubiquitin-proteosome system \\
\hline Ubpl0p & 0 & $0-1$ & 1 & 0 & 0 & Ubiquitin-proteosome system \\
\hline Ppalp & I & I & I & I & 0 & Vacuolar ATPase subunit \\
\hline
\end{tabular}

ASP, A. fumigatus, N. fischeri, A. oryzae, A. nidulans; SOR, N. crassa, G. zeae, and M. grisea; BAS: C. neoformans and U. maydis; Scer, S. cerevisiae; Spom, S. pombe.

MOD-A, MOD-D and MOD-E [51-53]. VIB-1, a putative regulator of conidiation and $\mathrm{HI}$ in N. crassa, is orthologous to Penicillium chrysogenum PhoG and A. nidulans PacG, which were annotated as putative non-repressible acid phosphatases via transformation experiments $[50,54,55]$. There is no apparent orthologs in yeasts, although, VIB-1 is a distant homolog of the Ndt80p transcription factor from S. cerevisiae [56]. The distribution of MOD-A orthologs also appears to be limited to filamentous ascomycetes. Only A. oryzae, but not other Aspergilli, contains an ortholog of MOD-A, implicated in ascomycete-specific functions such as regulation of growth arrest during $\mathrm{HI}$ and female organ formation in P. anserina [51]. On the contrary, MOD-D and MOD-E display a very high level of sequence conservation and have a much wider phyletic distribution with homologs in all fungi and higher eukaryotes. MOD-D, a G protein alpha subunit, is orthologous to GpaB and GanB from A. fumigatus and $A$. nidulans, respectively $[57,58]$.
The degree of sequence conservation seems to be linked to the relative importance of the biological function and more conserved proteins appear to be functional orthologs. The similarity between VIB- 1 and Ndt80p, a transcription factor involved in regulation of sporulation and meiosis in S. cerevisiae [56], suggests that phoG and pacG may encode a transcriptional regulators of the acid phosphatase, rather than the enzyme itself [59]. MOD-D and MOD-E have been shown to function as an alpha subunit of heterotrimeric G protein, and an HSP90 family molecular chaperone, respectively $[52,53]$. P. anserina MOD-E, in addition to suppressing HI, is involved in regulation of development and the sexual cycle $[53,60]$. The MOD-E/HSP90 function during the sexual cycle appears to be conserved from fungi to mammals [61]. Mammalian HSP90 family chaperones also mediate the unfolded protein response to endoplasmic reticulum stress through regulation of the secretory pathway, cell cycle and programmed cell death $[61,62]$. 
Table 4: Putative apoptotic mediators absent in S. cerevisiae

\begin{tabular}{|c|c|c|c|c|c|c|}
\hline Protein/Domain & ASP & SOR & Scer & Spom & BAS & Biological function/process \\
\hline TRAF-3 & I & 1 & 0 & 0 & 1 & Caspase dependent apoptosis \\
\hline Mst3/STK24 & I & $0-1$ & 0 & 2 & $0-1$ & Caspase dependent apoptosis \\
\hline PARP & 1 & I & 0 & 0 & 0 & Caspase independent apoptosis \\
\hline AMID & $1-2$ & $0-1$ & 0 & 0 & 1 & Caspase independent apoptosis \\
\hline GRIM-I9 & 1 & 1 & 0 & 0 & $\mathrm{I}-2$ & Electron transport, NADH ubiquinone oxidoreductase \\
\hline NDUFSI & i & I & 0 & 0 & 1 & Electron transport, NADH ubiquinone oxidoreductase \\
\hline APAF & $3-8$ & $0-2$ & 0 & 0 & 0 & NTP binding, hetero-oligomerization \\
\hline I2R-LO & I & $0-1$ & 0 & 0 & 0 & Peroxidation of arachidonic acid \\
\hline I5-LO & I & $0-1$ & 0 & 0 & 0 & Peroxidation of arachidonic acid \\
\hline PTDSR/PSR & I & I & 0 & 0 & I & Recognition of apoptotic cells \\
\hline
\end{tabular}

ASP, A. fumigatus, N. fischeri, A. oryzae, A. nidulans; SOR, N. crassa, G. zeae, and M. grisea; BAS: C. neoformans and U. maydis; Scer, S. cerevisiae; Spom, S. pombe.

Besides HI suppressors, Aspergilli also possess orthologs of $P$. anserina idi-2, idi-4, idi-6 and idi-7 genes (Table 2) induced by heterokaryon incompatibility and implicated in autophagy in response to starvation and sporulation and in regulation of sexual differentiation [8,63-65]. IDI6 and IDI-7 proteins seem to be highly conserved across fungal species; while IDI-2 and IDI-4 are poorly conserved and their distribution is limited to filamentous fungi. No detectable homologs of IDI-1 and IDI-3 are found in Aspergilli and an IDI-2 ortholog is only present in A. oryzae. Autophagic serine protease IDI-6 is orthologous to A. fumigatus Alp2 that has been shown to function in regulation of sporulation as well as pathogenesis in A. fumigatus [66]. Likewise, IDI-4 an ortholog of the A. fumigatus JlbA, a putative bZIP transcription factor induced by amino acid starvation [67].

Many HI-associated genes have wide phyletic distribution and are well-conserved across filamentous fungi. Some are involved in autophagy, suggesting that the incompatibility function might have evolved by recruiting components of the cellular system controlling adaptation to starvation [11]. In addition, cytological alterations during HI in P. anserina are similar to those observed during starvation and treatment with rapamycin, an inhibitor of the TOR (target of rapamycin) signaling pathway that controls autophagic degradation in S. cerevisiae [68]. Yet, many seem to perform unrelated functions such as regulation of development or sexual differentiation, implying that heterokaryon incompatibility may have utilized components of these cell programs as well.

\section{Downstream PCD machinery}

In addition to HI, filamentous fungi appear to possess a wide range of PCD reactions triggered by various death stimuli. In Aspergilli, the apoptotic-like phenotypes and are observed during entry into stationary phase and sporulation and on exposure to certain antifungal agents, peptides, and sphingosines $[4,6,7,69,70]$. Similarly, in $N$. crassa, morphological changes during the HI reaction, starvation, and DNA damage response resemble apoptosis $[9,10,71]$. The apoptotic machinery of filamentous fungi may share some key components with yeast and mammalian systems. First, we looked for homologs of apoptotic proteins in $S$. cerevisiae, which can undergo PCD in response to nutritional and oxidative stresses, plant antifungal peptides, hydrogen peroxide, or during aging and mating [72-75].

To identify candidate apoptosis-associated proteins in the Aspergilli, BLASTp similarity searches were performed with yeast apoptotic proteins as queries. Homologs of more than 30 yeast proteins were detected including metacaspases and caspase-regulating serine protease HtrA2 (Table 3). Phylogenetic analysis shows that many Aspergillus proteins are in one-on-one orthologous relationships with $S$. cerevisiae, $S$. pombe, and basidiomycete proteins (data not shown).

BLASTp and HMM searches identified homologs of 50 human and mouse apoptotic proteins in the Aspergilli [see Additional file 1 ]. Similar to yeasts, filamentous ascomycetes lack the upstream metazoan apoptotic regulators including members of the bax/bcl-2 family and p53, while downstream components of the apoptotic machinery appear to be shared. Interestingly, many Aspergillus proteins are more similar to their human counterparts such as AMID, BIR1, HtrA, and CulA, than to yeast homologs. Thus, the tree topology of the AIF family confirmed that Aspergilli proteins are more closely related to human AMID than to S. cerevisiae Aif1p, which clustered together with plant homologs [see Additional file 2 ]. Moreover, homologs of several key components of the mammalian apoptotic machinery, including AmsH and Poly(ADP-ribose) polymerase (PARP), are not detected in S. cerevisiae (Table 4). 
At least two Aspergilli proteins appear to be functional homologs to their mammalian counterparts. The enhanced PARP and caspase-like activity reported in A. nidulans during sporulation-induced PCD is consistent with the presence of both metacaspase-dependent and independent apoptotic pathways $[70,76]$. In addition, the metacaspase-independent apoptosis pathway was shown to operate in A. fumigatus during stationary phase and treatment with fungicidal sphingoid bases and antifungal agents $[4,69]$. For the rest of the fungal proteins, further experimental characterization is required before any conclusions can be drawn regarding their involvement in PCD. Many yeast and mammalian apoptotic proteins appear to be involved in regulation of cell programs monitoring the cell status such as maintenance of genome integrity, cell cycle control, glycolipid metabolism, and ubiquitin-dependent proteolysis [see Additional file 2] [77]. It is likely that at least non-apoptotic function is conserved in both fungi and metazoa. The results also support the idea that complex development and differentiation in filamentous fungi may require additional PCD pathways or their components not found in unicellular yeasts [78].

\section{Conclusion}

Our analysis identified more than 100 putative PCD-associated genes in this genus, suggesting a complex uncharacterized regulatory network. Their further characterization may help expand the range of currently available treatments for invasive aspergillosis. The list includes lineagespecific protein families as well as conserved core components of the ancestral PCD machinery shared by all fungi and metazoa.

The most divergent group is comprised of putative $\mathrm{HI}$ inducers such as STAND, HET-s/LopB and HET domain proteins that show extreme variability in sequence, copy number and domain composition. The STAND NTPases are predicted to interact with different types of effector/ signaling components and function as key integrators of stress and nutrient availability signals. On the other end of the spectrum are HI-associated proteins that show broad phyletic distribution and high sequence conservation. They tend to be involved in regulation of development, sexual differentiation, and stress reactions, suggesting that the HI function in filamentous fungi may have evolved by recruiting components from these preexisting pathways $[11,52,53]$.

Further analysis revealed homologs of the yeast PCD proteins in ascomycete and basidiomycete species, further supporting the view that genes encoding the ancestral apoptotic machinery evolved with early eukaryotes [7780]. Phylogenetic relationships among the putative PCD associated proteins appear to be complex and many Aspergillus proteins show a greater similarity to mamma- lian than to yeast proteins. In addition, homologs of several mammalian apoptotic proteins including PARP and AMID are found in filamentous fungi, but not in the unicellular yeast such as $S$. cerevisiae, suggesting that the Aspergilli may serve as an alternative model to study mechanisms of cell death.

\section{Methods}

\section{Sequence similarity}

To identify human and mouse proteins implicated in PCD, we searched the Gene Ontology (GO) database [81] and the Apoptosis database [82]. Then, sequence similarity searches were performed using PSI-BLAST and Gapped BLAST against selected fungal genomes downloaded from GenBank. The searches were also performed against an inhouse database composed of whole-genome sequences of several fungal species from finished and ongoing sequencing projects. The $N$. fischeri genome sequence has been generated in the course of the genome sequencing projects at TIGR, The Institute for Genomic Research (Rockville, MD). Conserved protein domains were identified using the HMMer package [83].

\section{Phylogenetic Analysis}

Protein sequences were re-aligned using MUSCLE [84] and columns of low conservation removed manually. The alignments were then used to infer bootstrapped neighbor-joining and maximum-likelihood trees. The neighbor-joining trees were constructed using QuickTree [85] and the maximum-likelihood trees were constructed using the PHYLIP package [86], applying the JTT substitution model with a gamma distribution (alpha $=0.5$ ) of rates over four categories of variable sites. In general, the maximum-likelihood and neighbor-joining trees were congruent.

\section{Authors' contributions}

NDF performed the comparative analysis, interpreted the results and prepared the biological aspects of the manuscripts. JHB performed the phylogenetic analysis and allowed use of his Automated Phylogenetic Inference System (APIS). GDR initiated the project and contributed to the comparative analysis. JRW and WCN contributed to the bioinformatics discussion and planning stage of this project and helped drafting the manuscript.

\section{Additional material}

\section{Additional File 1}

Putative apoptotic mediators (mammalian protein homologs). Table indicating numbers of fungal homologs of mammalian apoptotic effectors and mediators.

Click here for file

[http://www.biomedcentral.com/content/supplementary/14712164-6-177-S1.xls] 


\section{Additional File 2}

Phylogenetic tree of the AMID family of proteins. Tree reconstruction was performed as described in the Methods section. The numbers indicate percent bootstrap values for internal branches.

Click here for file

[http://www.biomedcentral.com/content/supplementary/14712164-6-177-S2.doc]

\section{Acknowledgements}

Funding for the study for each author and for manuscript preparation was provided by the National Institute of Allergy and Infectious Diseases (UOIA I 48830 and R2I A1052236), USA, the Wellcome Trust, UK and the Fondo de Investigaciones Sanitarias, Spain. We also thank Michael Galperin and Vinita Joardar for insightful discussions and Catherine Ronning, Brian Haas, Paolo Amedeo and Joshua Orvis for computer support. Special thanks go to Louise Glass and Karine Dementhon for valuable comments. We would also like to thank the reviewers for their helpful comments.

\section{References}

I. Latge JP: Aspergillus fumigatus and aspergillosis. Clin Microbiol Rev 1999, I 2:310-350.

2. Wilson DM, Mubatanhema W, Jurjevic Z: Biology and ecology of mycotoxigenic Aspergillus species as related to economic and health concerns. Adv Exp Med Biol 2002, 504:3-17.

3. Gupta AK, Tomas E: New antifungal agents. Dermatol Clin 2003, 21:565-576.

4. Krishnan S, Manavathu EK, Chandrasekar PH: A comparative study of fungicidal activities of voriconazole and amphotericin B against hyphae of Aspergillus fumigatus. J Antimicrob Chemother 2005.

5. Cheng J, Park TS, Chio LC, Fischl AS, Ye XS: Induction of apoptosis by sphingoid long-chain bases in Aspergillus nidulans. Mol Cell Biol 2003, 23:163-177.

6. Krishnan S, Manavathu EK, Chandrasekar PH: A comparative study of fungicidal activities of voriconazole and amphotericin B against hyphae of Aspergillus fumigatus. J Antimicrob Chemother 2005.

7. Mousavi SA, Robson GD: Oxidative and amphotericin B-mediated cell death in the opportunistic pathogen Aspergillus fumigatus is associated with an apoptotic-like phenotype. Microbiology 2004, 150:1937-1945.

8. Pinan-Lucarre B, Paoletti M, Dementhon K, Coulary-Salin B, Clave C: Autophagy is induced during cell death by incompatibility and is essential for differentiation in the filamentous fungus Podospora anserina. Mol Microbiol 2003, 47:32I-333.

9. Marek SM, Wu J, Louise Glass N, Gilchrist DG, Bostock RM: Nuclear DNA degradation during heterokaryon incompatibility in Neurospora crassa. Fungal Genet Biol 2003, 40:126-137.

10. Jacobson DJ, Beurkens K, Klomparens KL: Microscopic and Ultrastructural Examination of Vegetative Incompatibility in Partial Diploids Heterozygous at het Loci in Neurospora crassa. Fungal Genet Biol 1998, 23:45-56.

11. Dementhon K, Paoletti M, Pinan-Lucarre B, Loubradou-Bourges N, Sabourin M, Saupe SJ, Clave C: Rapamycin mimics the incompatibility reaction in the fungus Podospora anserina. Eukaryot Cell 2003, 2:238-246.

12. Glass NL, Rasmussen C, Roca MG, Read ND: Hyphal homing, fusion and mycelial interconnectedness. Trends Microbiol 2004, |2:|35-|4|.

13. Glass NL, Jacobson DJ, Shiu PK: The genetics of hyphal fusion and vegetative incompatibility in filamentous ascomycete fungi. Annu Rev Genet 2000, 34: 165-186.

14. Saupe SJ, Clave C, Begueret J: Vegetative incompatibility in filamentous fungi: Podospora and Neurospora provide some clues. Curr Opin Microbiol 2000, 3:608-6/2.

15. Saupe SJ: Molecular genetics of heterokaryon incompatibility in filamentous ascomycetes. Microbiol Mol Biol Rev 2000, 64:489-502.
16. Saenz GS, Stam JG, Jacobson DJ, Natvig DO: Heteroallelism at the het-c locus contributes to sexual dysfunction in outcrossed strains of Neurospora tetrasperma. Fungal Genet Biol 200I, 34: I23-129.

17. Biella S, Smith ML, Aist JR, Cortesi P, Milgroom MG: Programmed cell death correlates with virus transmission in a filamentous fungus. Proc Biol Sci 2002, 269:2269-2276.

18. Coustou V, Deleu C, Saupe S, Begueret J: The protein product of the het-s heterokaryon incompatibility gene of the fungus Podospora anserina behaves as a prion analog. Proc Natl Acad Sci U S A 1997, 94:9773-9778.

19. Mir-Rashed N, Jacobson DJ, Dehghany MR, Micali OC, Smith ML: Molecular and functional analyses of incompatibility genes at het-6 in a population of Neurospora crassa. Fungal Genet Biol 2000, 30:197-205.

20. Milgroom MG, Cortesi P: Analysis of population structure of the chestnut blight fungus based on vegetative incompatibility genotypes. Proc Natl Acad Sci U S A 1999, 96: 105 I 8- 10523.

21. Saupe SJ, Clave C, Sabourin M, Begueret J: Characterization of hch, the Podospora anserina homolog of the het-c heterokaryon incompatibility gene of Neurospora crassa. Curr Genet 2000, 38:39-47.

22. Wu J, Saupe SJ, Glass NL: Evidence for balancing selection operating at the het-c heterokaryon incompatibility locus in a group of filamentous fungi. Proc Natl Acad Sci U S A 1998, 95: 12398-12403.

23. Sarkar S, lyer G, Wu J, Glass NL: Nonself recognition is mediated by HET-C heterocomplex formation during vegetative incompatibility. Embo / 2002, $21: 484$ I-4850.

24. Saupe $S$, Turcq B, Begueret J: A gene responsible for vegetative incompatibility in the fungus Podospora anserina encodes a protein with a GTP-binding motif and G beta homologous domain. Gene 1995, 162:135-139.

25. Anwar MM, Croft JH, Dales RB: Analysis of heterokaryon incompatibility between heterokaryon-compatibility $(h-c)$ groups $R$ and $G L$ provides evidence that at least eight het loci control somatic incompatibility in Aspergillus nidulans. J Gen Microbiol 1993, I39:1599-1603.

26. Saupe S, Descamps C, Turcq B, Begueret J: Inactivation of the Podospora anserina vegetative incompatibility locus het-c, whose product resembles a glycolipid transfer protein, drastically impairs ascospore production. Proc Natl Acad Sci U S A |994, 91:5927-5931.

27. Rao CS, Lin X, Pike HM, Molotkovsky JG, Brown RE: Glycolipid transfer protein mediated transfer of glycosphingolipids between membranes: a model for action based on kinetic and thermodynamic analyses. Biochemistry 2004, 43:|3805-138|5.

28. Brodersen P, Petersen M, Pike HM, Olszak B, Skov S, Odum N, Jorgensen LB, Brown RE, Mundy J: Knockout of Arabidopsis accelerated-cell-death I I encoding a sphingosine transfer protein causes activation of programmed cell death and defense. Genes Dev 2002, 16:490-502.

29. Cheng J, Park TS, Fischl AS, Ye XS: Cell cycle progression and cell polarity require sphingolipid biosynthesis in Aspergillus nidulans. Mol Cell Biol 2001, 21:6198-6209.

30. Mattjus P, Turcq B, Pike HM, Molotkovsky JG, Brown RE: Glycolipid intermembrane transfer is accelerated by HET-C2, a filamentous fungus gene product involved in the cell-cell incompatibility response. Biochemistry 2003, 42:535-542.

31. Saupe SJ, Kuldau GA, Smith ML, Glass NL: The product of the het$C$ heterokaryon incompatibility gene of Neurospora crassa has characteristics of a glycine-rich cell wall protein. Genetics 1996, I43:1589-1600.

32. Davies JR, Osmani AH, De Souza CP, Bachewich C, Osmani SA: Potential link between the NIMA mitotic kinase and nuclear membrane fission during mitotic exit in Aspergillus nidulans. Eukaryot Cell 2004, 3: I433- I444.

33. Smith ML, Micali OC, Hubbard SP, Mir-Rashed N, Jacobson DJ, Glass NL: Vegetative incompatibility in the het-6 region of Neurospora crassa is mediated by two linked genes. Genetics 2000 , 155:1095-1104.

34. Deleu C, Clave C, Begueret J: A single amino acid difference is sufficient to elicit vegetative incompatibility in the fungus Podospora anserina. Genetics 1993, 135:45-52. 
35. Anantharaman $\mathrm{V}$, Aravind L: New connections in the prokaryotic toxin-antitoxin network: relationship with the eukaryotic nonsense-mediated RNA decay system. Genome Biol 2003, 4:R8I.

36. Balguerie A, Dos Reis S, Ritter C, Chaignepain S, Coulary-Salin B, Forge V, Bathany K, Lascu I, Schmitter JM, Riek R, Saupe S): Domain organization and structure-function relationship of the HETs prion protein of Podospora anserina. Embo J 2003, 22:207|-208|.

37. Dalstra HJ, Swart K, Debets AJ, Saupe SJ, Hoekstra RF: Sexual transmission of the [Het-S] prion leads to meiotic drive in Podospora anserina. Proc Natl Acad Sci U S A 2003. 100:6616-6621.

38. Balguerie A, Dos Reis S, Coulary-Salin B, Chaignepain S, Sabourin M, Schmitter JM, Saupe SJ: The sequences appended to the amyloid core region of the HET-s prion protein determine higherorder aggregate organization in vivo. J Cell Sci 2004 I I 7:2599-26 I0.

39. Leipe DD, Koonin EV, Aravind L: STAND, a class of P-loop NTPases including animal and plant regulators of programmed cell death: multiple, complex domain architectures, unusual phyletic patterns, and evolution by horizontal gene transfer. I Mol Biol 2004, 343: I-28.

40. Graziani S, Silar P, Daboussi MJ: Bistability and hysteresis of the 'Secteur' differentiation are controlled by a two-gene locus in Nectria haematococca. BMC Biol 2004, 2: 18

4I. Espagne E, Balhadere P, Penin ML, Barreau C, Turcq B: HET-E and HET-D belong to a new subfamily of WD40 proteins involved in vegetative incompatibility specificity in the fungus Podospora anserina. Genetics 2002, I 6 I:7|-81.

42. Girardin SE, Sansonetti PJ, Philpott DJ: Intracellular vs extracellular recognition of pathogens--common concepts in mammals and flies. Trends Microbiol 2002, 10:193-199.

43. Belkhadir $Y$, Subramaniam R, Dangl JL: Plant disease resistance protein signaling: NBS-LRR proteins and their partners. Curr Opin Plant Biol 2004, 7:391-399.

44. van der Biezen EA, Jones JD: The NB-ARC domain: a novel signalling motif shared by plant resistance gene products and regulators of cell death in animals. Curr Biol 1998, 8:R226-7.

45. Mushegian AR, Koonin EV: Unexpected sequence similarity between nucleosidases and phosphoribosyltransferases of different specificity. Protein Sci 1994, 3: I08I-I088.

46. Beeston AL, Surette MG: pfs-dependent regulation of autoinducer 2 production in Salmonella enterica serovar Typhimurium. I Bacteriol 2002, I 84:3450-3456.

47. Avila MA, Garcia-Trevijano ER, Lu SC, Corrales FJ, Mato JM: Methylthioadenosine. Int J Biochem Cell Biol 2004, 36:2I 25-2I 30.

48. Bok JW, Keller NP: LaeA, a regulator of secondary metabolism in Aspergillus spp. Eukaryot Cell 2004, 3:527-535.

49. Bok JW, Balajee SA, Marr KA, Andes D, Nielsen KF, Frisvad JC, Keller NP: LaeA, a Regulator of Morphogenetic Fungal Virulence Factors. Eukaryot Cell 2005, 4: I574-I582.

50. Xiang $\mathrm{Q}$, Glass NL: The control of mating type heterokaryon incompatibility by vib-I, a locus involved in het-c heter okaryon incompatibility in Neurospora crassa. Fungal Genet Biol 2004, 4l: 1063-1076.

5I. Barreau C, Iskandar M, Loubradou G, Levallois V, Begueret J: The mod-A suppressor of nonallelic heterokaryon incompatibility in Podospora anserina encodes a proline-rich polypeptide involved in female organ formation. Genetics 1998, 1 49:915-926.

52. Loubradou G, Begueret J, Turcq B: MOD-D, a Galpha subunit of the fungus Podospora anserina, is involved in both regulation of development and vegetative incompatibility. Genetics 1999 I 52:519-528.

53. Loubradou G, Begueret J, Turcq B: A mutation in an HSP90 gene affects the sexual cycle and suppresses vegetative incompatibility in the fungus Podospora anserina. Genetics 1997, | 47:58I-588.

54. Marx F, Haas H, Hofer S, Stoffler G, Redl B: Sequence and structure of Penicillium chrysogenum phoG, homologous to an acid phosphatase-encoding gene of Aspergillus nidulans. Gene 1995, 160:137-138.

55. MacRae WD, Buxton FP, Sibley S, Garven S, Gwynne DI, Davies RW, Arst HNJ: A phosphate-repressible acid phosphatase gene from Aspergillus niger: its cloning, sequencing and transcriptional analysis. Gene 1988, 71:339-348.

56. Hepworth SR, Friesen H, Segall J: NDT80 and the meiotic recombination checkpoint regulate expression of middle sporulation-specific genes in Saccharomyces cerevisiae. Mol Cell Biol 1998, I 8:5750-576I.

57. Han $\mathrm{KH}$, Seo JA, Yu JH: Regulators of G-protein signalling in Aspergillus nidulans: RgsA downregulates stress response and stimulates asexual sporulation through attenuation of GanB (Galpha) signalling. Mol Microbiol 2004, 53:529-540.

58. Liebmann B, Muller M, Braun A, Brakhage AA: The cyclic AMPdependent protein kinase a network regulates development and virulence in Aspergillus fumigatus. Infect Immun 2004, 72:5193-5203.

59. Xiang Q, Glass NL: Identification of vib-I, a locus involved in vegetative incompatibility mediated by het-c in Neurospora crassa. Genetics 2002, I62:89-101.

60. Loubradou G, Begueret J, Turcq B: An additional copy of the adenylate cyclase-encoding gene relieves developmental defects produced by a mutation in a vegetative incompatibility-controlling gene in Podospora anserina. Gene 1996, I 70: I19-123.

61. Szent-Gyorgyi C: A bipartite operator interacts with a heat shock element to mediate early meiotic induction of Saccharomyces cerevisiae HSP82. Mol Cell Biol 1995, I5:6754-6769.

62. Patil C, Walter P: Intracellular signaling from the endoplasmic reticulum to the nucleus: the unfolded protein response in yeast and mammals. Curr Opin Cell Biol 200I, I 3:349-355.

63. Dementhon K, Saupe SJ, Clave C: Characterization of IDI-4, a bZIP transcription factor inducing autophagy and cell death in the fungus Podospora anserina. Mol Microbiol 2004, 53:1625-1640.

64. Dementhon K, Saupe SJ: DNA-binding specificity of the IDI-4 basic leucine zipper factor of Podospora anserina defined by systematic evolution of ligands by exponential enrichment (SELEX). Eukaryot Cell 2005, 4:476-483.

65. Bourges N, Groppi A, Barreau C, Clave C, Begueret J: Regulation of gene expression during the vegetative incompatibility reaction in Podospora anserina. Characterization of three induced genes. Genetics 1998, I50:633-641.

66. Reichard U, Cole GT, Hill TW, Ruchel R, Monod M: Molecular characterization and influence on fungal development of ALP2, a novel serine proteinase from Aspergillus fumigatus. Int J Med Microbiol 2000, 290:549-558.

67. Strittmatter AW, Irniger S, Braus GH: Induction of jlbA mRNA synthesis for a putative bZIP protein of Aspergillus nidulans by amino acid starvation. Curr Genet 200I, 39:327-334.

68. Kamada $Y$, Sekito T, Ohsumi Y: Autophagy in yeast: a TORmediated response to nutrient starvation. Curr Top Microbio Immunol 2004, 279:73-84.

69. Mousavi SA, Robson GD: Entry into the stationary phase is associated with a rapid loss of viability and an apoptotic-like phenotype in the opportunistic pathogen Aspergillus fumigatus. Fungal Genet Biol 2003, 39:221-229.

70. Thrane C, Kaufmann U, Stummann BM, Olsson S: Activation of caspase-like activity and poly (ADP-ribose) polymerase degradation during sporulation in Aspergillus nidulans. Fungal Genet Biol 2004, 41:36I-368.

7l. Goldman GH, McGuire SL, Harris SD: The DNA damage response in filamentous fungi. Fungal Genet Biol 2002, 35:183-195

72. Burhans WC, Weinberger M, Marchetti MA, Ramachandran L, D'Urso G, Huberman JA: Apoptosis-like yeast cell death in response to DNA damage and replication defects. Mutat Res 2003, 532:227-243.

73. Eisler H, Frohlich KU, Heidenreich E: Starvation for an essential amino acid induces apoptosis and oxidative stress in yeast. Exp Cell Res 2004, 300:345-353.

74. Ligr M, Velten I, Frohlich E, Madeo F, Ledig M, Frohlich KU, Wolf DH, Hilt W: The proteasomal substrate Stm I participates in apoptosis-like cell death in yeast. Mol Biol Cell 200I, I 2:2422-2432.

75. Madeo F, Herker E, Wissing S, Jungwirth H, Eisenberg T, Frohlich KU: Apoptosis in yeast. Curr Opin Microbiol 2004, 7:655-660.

76. Hong SJ, Dawson TM, Dawson VL: Nuclear and mitochondrial conversations in cell death: PARP-I and AIF signaling. Trends Pharmacol Sci 2004, 25:259-264. 
77. Aravind L, Dixit VM, Koonin EV: Apoptotic molecular machinery: vastly increased complexity in vertebrates revealed by genome comparisons. Science 200I, 29 I:I279-1 284.

78. Koonin EV, Aravind L: Origin and evolution of eukaryotic apoptosis: the bacterial connection. Cell Death Differ 2002, 9:394-404.

79. Koonin EV, Galperin MY: Comparative Genomics and New Evolutionary Biology. In Sequence - Evolution - Function First edition. Boston, Dordrecht, London, Kluwer Academic Press; 2002:227-294.

80. Aravind L, Dixit VM, Koonin EV: The domains of death: evolution of the apoptosis machinery. Trends Biochem Sci 1999, 24:47-53.

81. Gene Ontology [http://www.geneontology.org].

82. Apoptosis database [http://www.apoptosis-db.org]. .

83. HMMer package [http://hmmer.wustl.edu]. .

84. Edgar RC: MUSCLE: a multiple sequence alignment method with reduced time and space complexity. BMC Bioinformatics 2004, 5: II3.

85. Howe K, Bateman A, Durbin R: QuickTree: building huge Neighbour-Joining trees of protein sequences. Bioinformatics 2002, I 8:1546-1547.

86. Retief JD: Phylogenetic analysis using PHYLIP. Methods Mol Biol 2000, 132:243-258.

Publish with Biomed Central and every scientist can read your work free of charge

"BioMed Central will be the most significant development for disseminating the results of biomedical research in our lifetime. "

Sir Paul Nurse, Cancer Research UK

Your research papers will be:

- available free of charge to the entire biomedical community

- peer reviewed and published immediately upon acceptance

- cited in PubMed and archived on PubMed Central

- yours - you keep the copyright

Submit your manuscript here:

http://www.biomedcentral.com/info/publishing_adv.asp
BiolMedcentral 